\title{
Challenges in Having Vaccines Available to Control Transboundary Diseases of Livestock
}

\author{
Charles E. Lewis ${ }^{1,2}$ and James A. Roth ${ }^{1,2 *}$ \\ 1Department of Veterinary Microbiology and Preventive Medicine, College of \\ Veterinary Medicine, lowa State University, Ames, lowa, USA \\ ${ }^{2}$ Interdepartmental Microbiology Program, College of Veterinary Medicine, lowa \\ State University, Ames, lowa, USA
}

*Corresponding authors: jaroth@iastate.edu

DOI: https://doi.org/10.21775/cimb.042.001

\begin{abstract}
The global human population is growing at a rapid rate leading to the need for continued expansion of food animal production to meet the world's increasing nutritional requirements. As a consequence of this increased production demand, the use of high volume, animal dense systems have expanded providing high quality protein at reduced costs. Backyard animal production has also expanded. This increased food animal production has facilitated the rapid spread, mutation, and adaptation of pathogens to new hosts. This scenario continues to drive the emergence and reemergence of diseases in livestock species increasing the urgency for development and availability of vaccines for transboundary animal diseases (TADs). Even though vaccines are widely recognized as being an essential tool for control of TADs, there are many scientific, economic, political, and logistical challenges to having vaccine available to control an outbreak. This article will focus on examples of the challenges associated with having vaccines available for emergency response, as well as the characteristics of "ideal" TAD vaccines, the need for complementary diagnostic assays, and hurdles involved in bringing efficacious veterinary $T A D$ vaccines to market including regulatory constraints and considerations for stockpiling vaccines for emergency use in non-endemic countries.
\end{abstract}


Examples will also highlight the complicated interplay between animal health and human health and demonstrate the lasting benefits that can be gained from an efficacious vaccine.

\section{Introduction}

As the global human population is growing at an exponential rate and expected to reach 9.8 billion people in 2050, there has been a corresponding, unprecedented expansion and growth of food animal production to meet the increasing protein demand to support human nutrition requirements (Roth, 2019). The United Nations Food and Agriculture Organization (FAO) estimates that, to meet this increased demand by 2050 , food production must increase by approximately $70 \%$ compared to 2005 production levels (Figure 1) (FAO., 2009). As a consequence of the expansion of both the global human and production animal populations, there has been an increase in the emergence and reemergence of animal diseases (Hassell et al., 2017). This increased demand has driven the trend towards high volume, animal dense systems which provide ample opportunity for the rapid spread of disease, as well as increased fitness pressure leading to mutation and adaptation of pathogens to new host species or increased disease severity in historically susceptible populations (Hassell et al., 2017). Livestock and poultry are a significant contributors to the economy of many countries, accounting for over half of United States agricultural cash receipts, often exceeding $\$ 100$ billion per year. The increasing human population is also leading to an increase in "backyard" animal production in both rural and urban environments. This can be an important source of high-quality protein and income for food insecure households (Roth, 2011). However, the backyard animals typically do not benefit from biosecurity, vaccines or other veterinary care and can be a source of infection with zoonotic diseases. The increase in concentrated animal feeding operations and in backyard animal production to feed the increasing human population increases the urgency for development and availability of vaccines for transboundary animal diseases.

Transboundary Animal Diseases (TADs) are a major threat to agriculture animal health, as well as human health, and are defined by the United Nations Food and Agriculture Organization (FAO) as those diseases that have the potential meet a combination of the following criteria: (1) they are highly contagious; (2) they have the potential to spread rapidly, irrespective of national borders; (3) they are associated 


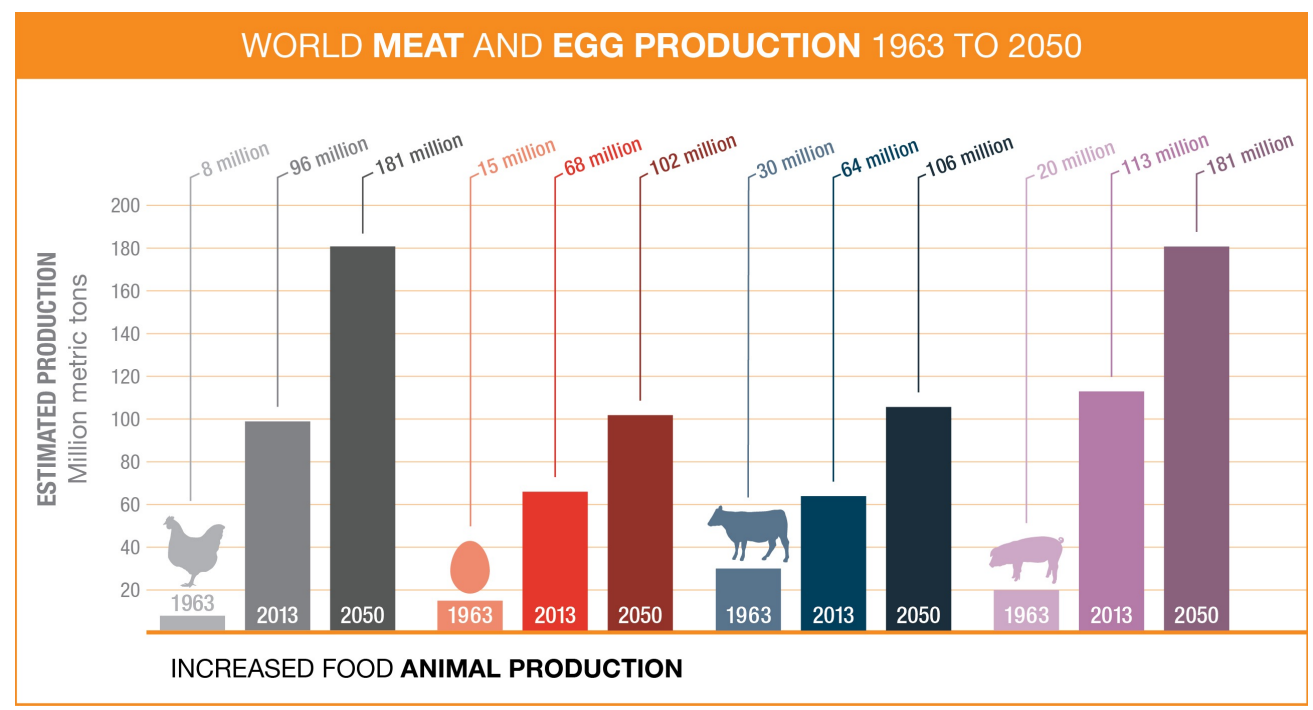

Figure 1. The United Nations Food and Agriculture Organization estimated world meat and egg production will need to increase by $70 \%$ from $2005 / 2007$ to 2050 to meet the needs of the growing population. From Roth, 2019.

with high mortality and/or morbidity in affected species; (4) they have the potential to affect food security and cause severe socioeconomic consequences; (5) they may be associated with public health concerns (FAO, 1996; Rossiter and Al Hammadi, 2009). Historically, TADs have had devastating consequences on both human and animal populations. Details of a few of these accounts will be discussed later in this article.

With increased globalization, the introduction of TADs into non-endemic areas can occur in a variety of ways. One of the most important translocation mechanisms include the domestic and global movement of diseased animals and contaminated animal products either as imports or food waste (Otte et al., 2004). Other means of introduction can occur through the importation of contaminated biological products or germplasm, the movement of people, and the migration of affected animal species. Climatic changes can lead to the natural spread of insect vectors and, in the case of some diseases, shifts in wind currents can lead to the spread of diseases (Jones et 
al., 2013). A TAD can rapidly become endemic in introduced areas threatening naive contact countries, which increases the likelihood of continued spread and further difficulty in gaining control of the outbreak, ultimately leading to greater impacts on food security (Otte et al., 2004). This dire situation is exacerbated in situations in which an efficacious and cost-effective vaccine is not available. A prime example of how rapidly and widely a disease can disperse without an available vaccine to implement as a control measure can be seen in the spread of African swine fever (ASF) disease in eastern Europe and Asia. ASF will be discussed in detail later in this review, as well as discussion on Foot-and-Mouth Disease (FMD), as these two diseases will be compared in regards to strategies towards developing "ideal" TAD vaccine platforms and their potential use as a component to control the impact of the disease.

There are numerous tools and approaches utilized to control the spread and damage created by the incursion of a TAD into a non-endemic area. These can include the control of movement of animals and people between areas, implementing and heightening biosecurity at the farm level, depopulation of infected and in-contact herds, epidemiologic trace back and trace forward of cases, implementation of rapid diagnostics, and mass vaccination. Implementation of vaccination campaigns are based on the overall objective and can include vaccinate-to-kill, vaccinate-toslaughter, or vaccinate-to-live strategies (Barnett et al., 2015b; Grubman and Baxt, 2004). The availability of TAD vaccines is of paramount importance for maintaining and advancing animal health, public health, and food production and security. They serve as a cost-effective methods to control and prevent animal disease, lead to increased high-quality protein availability, expand the efficiency of food production, as well as functioning to reduce or prevent the transmission of zoonotic and foodborne infections to people (Roth, 2011).

Even though vaccines are widely recognized as being an essential tool for control of TADs, there are many scientific, economic, political, and logistical challenges to having vaccine available to control a TAD outbreak. In this review we will discuss three transboundary animal diseases as different examples of the challenges associated with having vaccines available for emergency response to TADs (foot and mouth disease, African swine fever, and Nipah virus infection). The review will also focus on the characteristics of "ideal" TAD vaccines and the need for complementary 
diagnostic assays, hurdles involved in bringing efficacious veterinary TAD vaccines to market including regulatory constraints, and considerations for stockpiling vaccines for emergency use in non-endemic countries. The review will conclude with the example of the use of a veterinary vaccine for the successful, global eradication of rinderpest and its relation to increased food security and indirect impacts on human disease and public health. This will highlight the complicated interplay between animal health and human health and demonstrate the lasting benefits that can be gained from an efficacious vaccine. The rinderpest example will also demonstrate how introduction of a TAD can lead to famine, increased incidence of indirectly related disease in humans, and ultimately lead to the death of people and millions of animals.

\section{Foot-and-Mouth Disease}

As a transboundary animal disease, Foot and Mouth Disease (FMD) is perhaps the most important pathogen of livestock worldwide. It is a highly contagious, clinically acute, viral disease affecting members of Artiodactyla (cloven-hoofed animals), caused by the Foot and Mouth Disease Virus (FMDV), a member of the Apthovirus genus in the family Picornaviridae (Rweyemamu et al., 2008). The effects of this disease are of greatest concern, at least to the production livestock industry, in cattle and domestic swine, though disease has been reported in at least 70 species of wild animals, including wild ruminants and feral swine, which can play a significant role in its epidemiology (Alexandrov et al., 2013; Knight-Jones et al., 2016; Lee et al., 2017; Thompson et al., 2002; Thomson et al., 2003).

FMDV is a complicated virus with seven serotypes all having varying geographic distribution (O, A, C, Asia 1, SAT 1, SAT 2, and SAT 3) (Figure 2) (Grubman and Baxt, 2004; Rweyemamu et al., 2008). Globally, serotype $O$ is the most common and was responsible for a pan-Asian outbreak that began in 1990 and has subsequently engulfed many countries throughout the world. Serotype $C$ is considered to be eradicated, but is still utilized in the formulation of some multivalent vaccines (Jamal and Belsham, 2013). There are inconsistent levels of variability between the FMD serotypes and they collectively contain more than 60 viral strains with novel strains arising regularly. Continued circulation of the virus in the field and the quasispecies nature of the virus genome leads to the continued rise of new strains, which can continue to evolve to break-through vaccine-induced immunity (Grubman and Baxt, 
2004; Haydon et al., 2001; Jamal and Belsham, 2013). The vast majority of strains affect all susceptible species, yet some have more restricted host ranges (Arzt et al., 2011a). For instance, the O Cathay strain appears to only affect pigs. Immunity to one serotype does not reliably convey protection from other serotypes and intraserotype strain protection varies with the level of antigenic similarity (Lee et al., 2017; Rodriguez and Grubman, 2009).

The FMD virus can be found in most secretions and excretions from acutely affected animals, including expired air with animal species and virus strain accounting for differences in the amount of virus shed by each route. Animals are typically infected by inhalation, ingestion, or through abrasions in the skin or mucous membranes (Bartley et al., 2002; Grubman and Baxt, 2004). Pigs tend to produce large amounts of aerosolized virus, and the presence of a large, high-density swine herd may increase the risk of airborne spread to other animals. As pigs require much higher doses to be infected by inhalation, they are typically infected via ingestion of viruscontaminated material, while cattle are particularly susceptible to infection by the inhalation route (Arzt et al., 2011b; Stenfeldt et al., 2016). Mechanical transmission via fomites plays an important role in spread of this virus and people can also act as mechanical vectors by transporting the virus on their skin or clothing (Amass et al., 2004).

FMD is characterized by high morbidity and low mortality, though it does occasionally cause a fatal acute myocarditis that is typically limited to young animals. The hallmark clinical signs in affected species include a rapidly spreading acute onset, febrile illness with the formation of vesicular lesions on the tongue, dental pad, coronary band and teats (Arzt et al., 2011a; Stenfeldt et al., 2016). Though animals can and do recover from this disease, secondary bacterial infections of the vesicles can lead to chronic lameness, wasting, and mortality (Grubman and Baxt, 2004). As it affects production species, the presence of this disease in a domestic herd can lead to drastically lower yields and have devastating economic consequences. Resulting chronic lameness and permanent hoof damage can have direct impacts on the use of draft animals in many parts of the world where crop yields are dependent on animal labor (Knight-Jones and Rushton, 2013). Although adult animals typically recover, the associated morbidity is significant in naïve populations, including the presence of significant pain and distress in some animal species. Sequelae may 

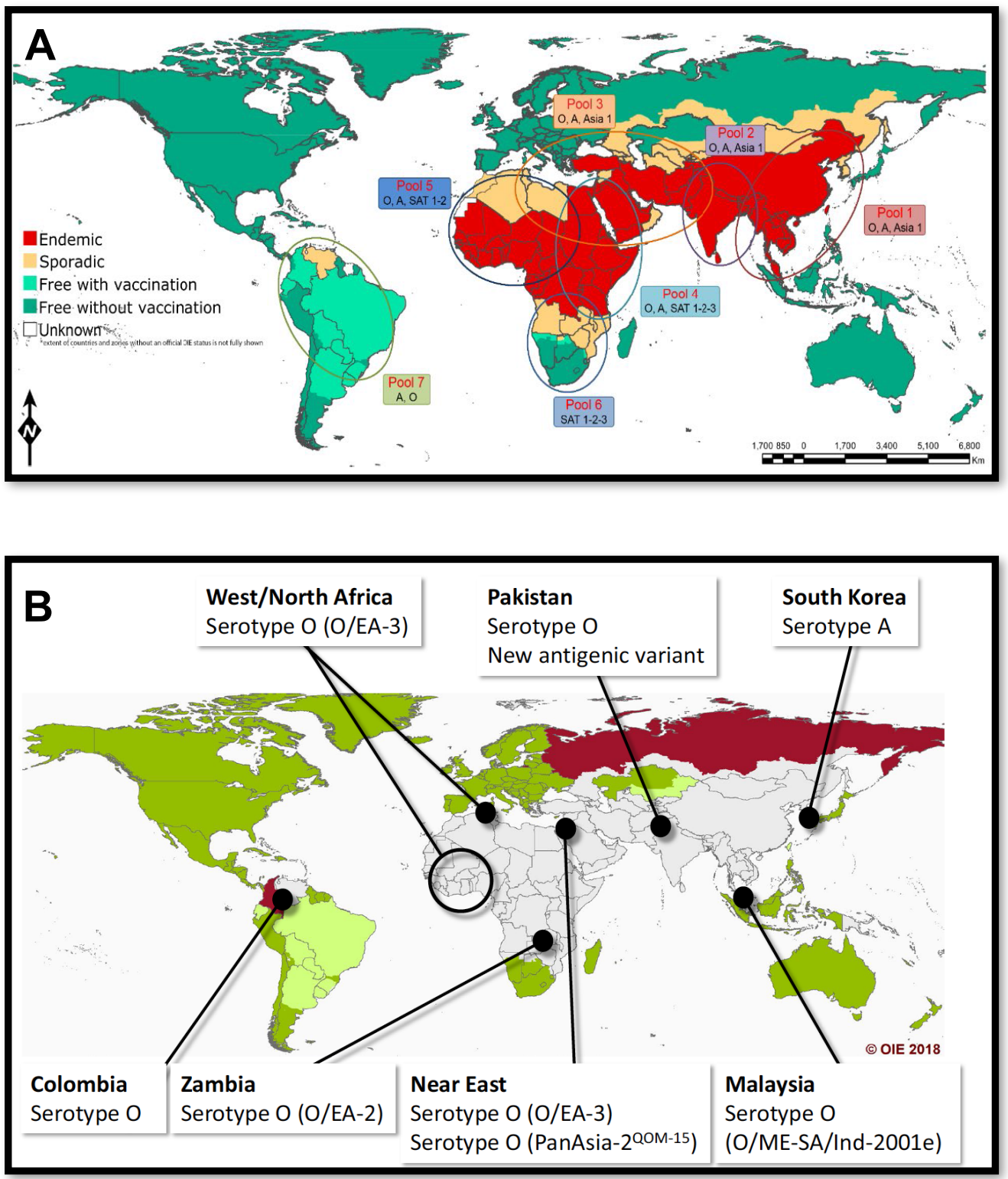

Figure 2. Geographic distribution of the seven serotypes of foot-and-mouth disease virus with the proposed disease status of individual countries in 2018 (A) and the major FMD events from that year (B). From King et al., 2018. 
include decreased milk yield, permanent hoof damage, heat-intolerance syndrome, and chronic mastitis (Grubman and Baxt, 2004).

After once being found nearly worldwide, FMD has now been eradicated from 70 countries (including North America, most of South America, Australia, Greenland, Iceland, and western Europe) through the control of movement of susceptible species and animal by-product movement and through the use of intricate mass vaccination and culling campaigns (Brito et al., 2017; Jamal and Belsham, 2013). FMD has not been reported in North America for more than 90 years, with the last outbreak occurring in 1929 (Bachrach, 1968). Even with the success of elimination, there are still over a hundred countries considered endemically or sporadically infected with the disease. Where FMD is endemic, animal production and performance are affected and these countries suffer major economic constraints secondary to trade embargoes that drastically reduced access to international markets. The potential effects of disease on smallholder farms can be significant. Nampanya et al estimated that losses associated with FMD could approach $60 \%$ of annual farm-based household income in Laos (Nampanya et al., 2016). Across all FMD-endemic countries, it is estimated that the disease costs $\$ 6.5-\$ 21$ billion US dollars (USD) annually in production losses (Knight-Jones and Rushton, 2013).

Outbreaks of FMD in countries that have previously eliminated the disease can be economically devastating due to the loss of trade and the cost of eradication with direct and indirect losses reaching into the billions of US dollars. The 2001 outbreak in the United Kingdom was estimated to cost $\$ 12$ billion USD and more than four million cattle and sheep were destroyed in order to reestablish disease free status and regain access to international markets (Thompson et al., 2002). A risk assessment estimated the hypothetical economic consequences of FMDV in the US to be up to $\$ 140$ billion USD with most of the cost impacting agricultural firms and consumers (Pendell et al., 2015).

\section{African Swine Fever}

Similar to FMD, African swine fever (ASF) is another high-consequence, transboundary animal disease causing great concern throughout the world swine industry. African Swine Fever Virus (ASFV) is a tick-borne Asfivirus, the sole member of the Asfarviridae family, and is the only known DNA arbovirus. The virus is large 
and complicated, containing over 170 proteins (Figure 3) (Chapman et al., 2008; Dixon et al., 2013; Dixon et al., 2005). ASFV is currently causing an unprecedented outbreak after its introduction and spread from the country of Georgia in both domestic and wild pigs, through Western Europe, and into Russia, ultimately leading to introduction into China, affecting the world's largest swine population and leading to the death of millions of domestic pigs (Dixon et al., 2005). It has been predicted this outbreak has resulted in a deficit of 25 million metric tons of pork in China in 2020 , equivalent to 55 billion pounds, which is approximately twice the annual production in the US and eight times the US pork exports for the same year (Speer, 2019).

ASFV is endemic in sub-Saharan Africa where it is hypothesized to have originated in warthogs but has since been established as a common virus of domestic pigs in the area. Outbreaks have occasionally occurred outside of Africa, but the virus was almost always brought under control and eradicated. One exception has been the persistence of the virus on the Italian island of Sardinia where uncontrolled movement of pigs, free-range production systems, and socioeconomic factors have complicated the situation (Gogin et al., 2013). There are more than 20 genotypes of ASFV and isolates demonstrating a full spectrum of virulence ranging from highly pathogenic strains to less virulent ones (Achenbach et al., 2017; De Villiers et al., 2010; Quembo et al., 2018). Depending on the strain, ASF can present with extremely high case-fatality, killing nearly the entire herd, or it can cause milder, nonspecific illness that can be extremely difficult to recognize. ASF only affects members of the pig family, Suidae, including domestic swine and wild boar. Wild suids, particularly warthogs, giant forest hogs, and bushpigs, serve as reservoirs and maintenance in Africa is via a complex sylvatic cycle involving transmission between the wild suids, argasid ticks, and domestic pigs (Costard et al., 2009; Dixon et al., 2019).

Even though ASFV is tick-borne, it can be effectively transmitted with or without a tick intermediate. Domestic pigs can shed virus in all secretions and excretions and, complicating recognition and control, a significant amount of shedding can occur prior to onset of clinical signs. As a high titer viremia results, massive environmental contamination is probable during necropsies, fighting between pigs, or if a pig develops melena (bloody stool). The ASF virus is resistant to many environmental 
conditions and persists in contaminated soil for long periods (Dixon et al., 2019). Outside of areas with the reservoir species, ASFV is most often transmitted directly between pigs via oral and nasal routes, but the pathogen can also be transmitted by iatrogenic means (Colgrove et al., 1969; Dixon et al., 2019; McVicar, 1984). Although all Ornithodoros species tested to date show susceptibility to infection with the virus, there appears to be varying degrees of vector competence. As a TAD, ticks play a limited role in ASF transmission when compared to the role played by movement of infected animals and animal products (EFSA, 2010).

Non-tickborne infection occurs after virus penetrates the animal's mucous membrane through direct contact with infected pigs or the environment, but most infections are thought to occur after either inhalation or ingestion. As ASFV can persist in tissues after death, significant spread can occur by feeding uncooked or undercooked, contaminated pig swill. Virus can also spread on fomites, including vehicles, feed, and equipment and the virus has been reported to persist for days to weeks in feces or urine under virus-favorable conditions (Costard et al., 2009; Dixon et al., 2019).

African swine fever causes a hemorrhagic disease in domestic pigs and can occur in varying forms from highly lethal, with case-fatality rates reaching $100 \%$, to subclinical disease (Rock, 2017; Villeda et al., 1995; Villeda et al., 1993). It can present as peracute, acute, subacute, or chronic illness and the progression is generally correlated with the virus isolate. Sudden death without overt signs of disease (peracute presentation) can be the first sign of infection in a herd. Acute cases typically present with high fever, anorexia, lethargy, and recumbency with a reluctance to move. Pigs may have erythema and/or cyanotic blotching of the skin predominately affecting the ears, tail, and lower limbs and pigs can also present with diarrhea, constipation, vomiting, signs of abdominal pain, or hemorrhagic signs (including epistaxis and petechial/ecchymotic skin lesions). Subacute disease has similar signs with decreased severity, while chronic disease can present as an intermittent low-grade illness accompanied by depression and decreased appetite. Host and viral factors responsible for the variation in disease remain poorly understood. From a disease control perspective, it must be noted that ASFV can establish long-term persistent infections in warthogs and domestic pigs that survive acute infection (De Kock et al., 1940; DeTray, 1957; Mebus and Dardiri, 1980; Rock, 2017; Thomas et al., 2016; Wilkinson et al., 1983). 
Currently, there are no effective vaccine candidates available to combat ASF. The history and progress towards the development of effective biologic countermeasures will be discussed in the next section. Without an effective vaccine, ASF control is based on early detection, isolation, and culling of infected herds, and strict biosecurity measures to prevent introduction of the virus onto new farms. Depending on the situation, these measures can have varying success rates.

\section{The "ideal" livestock TAD vaccine}

The basis of vaccination is to simulate the development of naturally acquired immunity by inoculation of immunogenic components of a target pathogen, or similar surrogate, while not causing disease (Meeusen et al., 2007). Both veterinary and human vaccinology has made immense progress since its inception when Edward Jenner's inoculation with cowpox, a zoonotic disease, as a surrogate for prevention of smallpox disease in humans (Adams et al., 2011). This humble beginning demonstrates the close relationship between both human and animal infectious disease research, but even with the shared beginnings and close relationship, the criteria for what is considered successful vaccination and the "ideal" vaccine can be drastically different for veterinary and human biologics. Within veterinary vaccinology, there can be diverse benchmarks between target animal groups being considered. For instance, human vaccines share similar goals as companion animal ("pet") vaccination where the health and well-being of the individual animal are of chief concern. While for the livestock industry vaccination aims to safeguard and expand the economic benefit to the farmer with the main objective being to improve production of the animal and protect the herd and, therefore, maintain food security. In the case of zoonotic diseases affecting livestock, vaccination can also be used to reduce or eliminate the risk of transmission to humans involved in production and the end consumer, while also improving animal productivity. Vaccination of livestock also contributes to the welfare of animals and to the reduced need for antibiotics to treat infection (Adams et al., 2011; Meeusen et al., 2007; Roth, 2011).

The process of developing and bringing veterinary vaccines to market can be time consuming and expensive. Since most private companies are profit driven, research and development investment decisions in the veterinary industry are based on the potential of products to generate sales and recuperate costs in a given target market, this can be difficult to accomplish with many emerging infectious diseases and TADs 
(Hardham and Lamichhane, 2013; Heldens et al., 2008). The potential financial returns to the manufacturer on animal biologics are typically much less than their human counterparts due to lower prices and smaller market sizes, yet their complexity and range of potential hosts and pathogens are greater. This ultimately results in lower overall investment in research and development. However, compared to human vaccine development, veterinary vaccines generally have less stringent regulatory requirements and shorter market to launch times with quicker return on investments. Animal vaccine development has the advantage of the ability to do challenge studies in the intended species. In addition, legal liabilities for manufacturers are less for animal vaccines compared to human vaccines. Aside from the safety and efficacy profiles, the predominate factor that determines the success of a vaccine is an effective commercialization plan resulting in its use in the field (Heldens et al., 2008; Meeusen et al., 2007).

The following characteristics of an "ideal" TAD vaccine are desirable, but not all are necessarily essential or currently even considered scientifically feasible:

- Shown to be pure, safe, potent, and efficacious in the target species

- Provide rapid onset with long duration of immunity with a single dose

- Are effective in the presence of maternal antibody

- Show lack of interference with other vaccines used in livestock

- Safe for manufacturing under BSL2 conditions when produced in a diseasefree country

- The organism used to produce the vaccine is not considered a select agent in the U.S.

- Can be produced with cost-effective manufacturing - the cost of the product must be beneficial to the manufacturer as well as the consumer

- Are safe for use in food production animals with no, or reasonably short, withdrawal time for animal products for human consumption

- Are considered non-hazardous for humans accidentally exposed to the vaccine

- Safety and efficacy demonstrated in multiple species (where applicable)

An important consideration for TAD vaccines is the availability of a companion diagnostic assay that allows detecting infection in vaccinated animals (DIVA). This is typically accomplished by discriminating the antibody responses that are vaccine- 
induced from those induced during infection with the wild-type virus. For example, FMDV vaccination induces the development of antibodies to virus capsid structural proteins, whereas infection induces antibodies to both structural and non-structural proteins. The non-structural proteins are required for FMDV replication and are conserved across all serotypes and strains. To be able to utilize a DIVA diagnostic for post-vaccination surveillance, the vaccines utilized must be purified to the point that they are free of the non-structural proteins (Barnett et al., 2015b; Clavijo et al., 2004). For several TADs of livestock, effective conventional vaccines are available but their use is restricted due to their interference with disease surveillance that is dependent on determining animal infection status based on serological assays. DIVA companion diagnostics may not be required in situations when vaccinated animals are intended to go directly to slaughter as these animals are removed from the national herd. Use of non-DIVA vaccines in non-endemic countries in animals not intended for slaughter has the potential to result in loss of the country's disease-free status from the World Organization for Animal Health (OIE). FMD in cattle is a classic example of this. Even though efficacious inactivated FMD vaccines have been available for decades, they are not used in non-endemic countries as this would forfeit the country's OIE disease free without vaccination status and, therefore, compromise continued international trade (Barnett et al., 2015a, b). The following subsections will discuss more of the specifics concerning available FMD vaccines and the importance of DIVA capability in regards to eradication after introduction to a non-endemic area as well as the historical attempts at producing an efficacious vaccine for ASF and why an effective vaccine has remained elusive.

\section{Foot-and-Mouth Disease Vaccines}

Vaccination for FMDV is an essential component of planning for emergency response control measures and is also routinely used to control the disease in endemic countries. Historically, FMD vaccination has been used to successfully eliminate the disease throughout most of the western hemisphere. The presence of numerous serotypes compounds the complicated nature of vaccination as vaccination of animals with one serotype does not necessarily confer protection against other serotypes (Grubman and Baxt, 2004). In actuality, the vaccine used can even fail to provide adequate protection against other subtypes within the same serotype. Traditional FMDV vaccines are produced from live, infectious virus grown in mass quantities in cell culture that is then inactivated, purified, and adjuvanted 
(Robinson et al., 2016; Rodriguez and Grubman, 2009). These traditional inactivated vaccines have fostered the successful elimination of this disease from many areas of the world and have allowed for the control and re-elimination after incursion into nonendemic areas. This formulation is the standard vaccine type for stockpiling in all of the FMD Vaccine Banks as vaccine antigen concentrate (inactivated, non-adjuvanted antigen concentrate) which can be stored over liquid nitrogen for extended periods of time and allows for rapid emergency formulation into finished vaccine (Lombard and Fussel, 2007; Robinson et al., 2016). Though these traditional vaccines have been used successfully for eradication, they have their disadvantages, including the requirement of cold chains when deploying the vaccine, the need for highcontainment vaccine production facilities capable of working with infectious virus, time required to finish the concentrate into final vaccine, and the possibility of release of live or inadequately inactivated virus from manufacturing sites (Grubman and Baxt, 2004; OIE, 2013).

The concerns posed by traditional, inactivated vaccines have given rise to research into numerous novel FMDV vaccine platforms. Historically, there have been problems associated with the development of attenuated vaccines including unstable phenotypes, differences in pathogenesis between target species, and development of attenuation to the point that the virus does not consistently produce a protective immune response (Rodriguez and Grubman, 2009). Advances in cDNA technology have allowed some progress towards a phenotype stable attenuated virus, including the engineering of a serotype A12 strain lacking the leader protein coding region that demonstrated attenuation in cattle but only partially protected the animals from subsequent wild-type FMDV challenge (Brown et al., 1996; Mason et al., 1997). Inoculation of swine with the same candidate virus prevented clinically apparent disease, lack of transmission to naïve swine, and provided partial protection from wild-type challenge. When produced as a chemically inactivated and adjuvanted finished vaccine, the resulting biologic induced protection similar to that produced by finished vaccine utilizing the wild-type virus (Chinsangaram et al., 1998). Vaccines produced from viruses engineered in this fashion may provide a means of overcoming the risk of production using their highly virulent wild-type parent strains (Cao et al., 2016). 
Without effective vaccination, traditional tools to control FMD in a previously FMDfree country are limited to preventing the movement of animals, heightened on-farm biosecurity, stamping out of affected populations (depopulation of all infected herds and in-contact herds as soon as possible), trace back and trace forward of cases 28 days prior to the start of the outbreak, and the rapid deployment of effective diagnostics. Other components of effective control programs are discussed later in this review (Barnett et al., 2015a; Grubman and Baxt, 2004).

\section{African Swine Fever Vaccines: hurdles and progress}

Despite being first described in 1921, effective vaccines protecting against ASF still remain elusive, leaving mass culling the only effective disease control option (Bellini et al., 2016; Montgomery, 1921; Rock, 2017). As ASF is one of the most significant emerging disease threats for the swine industry worldwide, development of vaccination strategies is paramount to limiting the potential devastation this disease may cause. It is thought that vaccination against this virus will be possible in the future based on knowledge that pigs that do recover from infection develop protection against reinfection with a homologous strain of the virus (King et al., 2011; Lacasta et al., 2015; Leitão et al., 2001; Mebus and Dardiri, 1980).

Typical of viral infections, both humoral and cellular immunity have been shown to be important for protection in ASFV infected pigs, but there is a lack of understanding of the specific mechanisms mediating anti-ASFV immunity and there have been no definitive correlates of protection established (Argilaguet et al., 2012; King et al., 2011; Lacasta et al., 2015; Oura et al., 2005). Viral proteins that function as protective antigens need to be identified, along with an understanding of the circulating strain variations, further understanding of viral pathogenesis, and to be able to produce broadly-effective vaccines offering cross-protection against relevant ASFV strains (Rock, 2017). As this is a large, complicated DNA virus, there are many proteins to evaluate. To be suitable for use under emergency conditions in nonendemic countries, the eventual vaccines must be DIVA compatible.

In pigs that have been naturally infected with low virulent strains of ASFV and for pigs inoculated with viruses attenuated by traditional methods, protective immunity is induced against homologous (rarely heterologous) virus challenge, but the conditions of cross protection are not well understood. Some strains produce levels of cross 
protection while those that appear to be closely related do not (King et al., 2011; Lacasta et al., 2015; Leitão et al., 2001; Mebus and Dardiri, 1980; Mulumba-Mfumu et al., 2016). Because of this, traditional live-attenuated vaccines are characterized by absent clinical signs and reduction in viremia and are thought to be protective due to early control of virus replication (Rock, 2017). Production processes involving live, infectious virus leads to similar hurdles as those described for FMDV, particularly regarding concerns of inadvertent release from a manufacturing facility. Attempts at engineering attenuated viruses for the purpose of vaccination has provided some progress towards a viable vaccine, but the effects of gene deletion on attenuation and immunogenicity appear to be strain dependent and inconsistent (Abrams et al., 2013; Afonso et al., 1998; Neilan et al., 2002; O'Donnell et al., 2015a; O'Donnell et al., 2015b; O'Donnell et al., 2016). Significant safety concerns have also been a major issue for live-attenuated ASFV vaccines, as shown by the first ASF vaccine study that lead to the development of chronic ASF after the originating virus had been attenuated by serial passage in bone marrow cell culture (Manso-Ribeiro et al., 1963). In general, the suitability of a live-attenuated approach to vaccination against ASFV is hindered by issues concerning efficacy, residual pathogenicity and reversion to virulence, and the development of long-term viral persistence. So far, attempts at conveying protection using a variety of inactivated vaccines have failed after numerous attempts. Future development of a vaccine using this approach appears unlikely (Abrams et al., 2013; Blome et al., 2014; Forman et al., 1982; Kihm et al., 1987; Mebus, 1988; Reis et al., 2016; Rock, 2017; Stone and Hess, 1967).

The potential use of subunit vaccines utilizing only specific protective viral antigens against ASFV within an optimized delivery or vector system may show the most promise towards a suitable vaccination approach. For these vaccines to be designed, the relevant protective antigens against ASFV and their natural antigenic diversity must be established. Results of attempts at producing an effective subunit vaccine so far indicate that additional unknown ASFV proteins are required for inducing full protective immunity (Argilaguet et al., 2013; Borca et al., 1998; Borca et al., 1994a; Borca et al., 1994b; Burmakina et al., 2016; Gomez-Puertas et al., 1996; Neilan et al., 2004; Rodríguez et al., 1993). Even though there are several viral proteins known to be correlated with protection, there is no single protein known to be sufficient for induction of sufficient protection in pigs to be utilized in an effective 
vaccine. This supports the conclusion that multiple viral antigens will be required for protection.

Recently, progress has been made towards the antigen selection critical for development of a subunit ASFV vaccine. Previously, using viral-vectored antigen pools, researchers tested the immunogenicity of twenty-eight different genes and demonstrated induction of antigen-specific cellular responses (Netherton et al., 2019). Goatley et al (2020) have determined that different combinations of antigens and doses could successfully induce cellular and humoral immune responses capable of whole virus recognition, yet there were no clear correlates of protection that could be used to predict outcomes after challenge with virulent ASFV. Recent work describes the induction of both antigen and ASFV-specific antibody and cellular responses with different viral-vectored pools of antigen that were selected based on their immunogenicity in pigs. One of the tested pools that consisted of eight viralvectored genes provided $100 \%$ protection in pigs after an otherwise fatal challenge with ASFV. The surviving animals did develop a viremia as well as clinical signs postchallenge. Further studies were recommended to determine the ability of the animals to clear virus and, importantly, if the vaccinates are able to shed infectious virus capable of transmission to naïve animals (Goatley et al., 2020). Even though this study utilized genotype I antigens and challenge, other studies have suggested that there may exist some level of cross-protection between the two genotypes with possible differences in T-cell or antibody epitopes (Gallardo et al., 2018; Goatley et al., 2020; Mur et al., 2013). There is still the need to define correlates of protection, the requirement for reimmunization with booster vaccination, and if other antigens may be utilized to improve the efficacy of the vaccine (Goatley et al., 2020). This work further validates the attractiveness of viral vector vaccine platforms as a potential mechanism for ASF control and continues to provide encouragement that there will one day be successful countermeasures to combat this terrible disease. Even with the significant amount of progress and expansion of knowledge concerning ASFV and the disease that it causes, there still remain significant challenges before an effective vaccine becomes a reality and can be incorporated into disease control measures. 


\section{Nipah virus}

Nipah virus (NiV) is a member of the family Paramyxoviridae, genus Henipavirus that emerged in dramatic fashion in Malaysia and Singapore in 1998, initially being mistaken for an atypical presentation of another viral disease, Japanese encephalitis. Nipah virus-induced disease in humans was characterized by severe febrile encephalitis that led to a case fatality rate of approximately $40 \%$ during the first outbreak. Although Pteropus bats are considered to be the predominant natural reservoir of the virus, human infections in Malaysia were found to be from zoonotic transmission from domestic pigs (AbuBakar et al., 2004; Chua et al., 2002; Clayton et al., 2013). Even with a quick national response and international assistance, the first outbreak ultimately led to the death of 105 people and the mass culling of almost half of the country's national pig herd, approximately 1.1 million head were lost. NiV is also suspected to be the causative agent of an outbreak in horses in the Philippines with subsequent transmission to humans (Ching et al., 2015). Since 2001, a different genotype of NiV has emerged with near annual outbreaks occurring in Bangladesh where sustained human to human transmission is responsible for continued spread of the disease with a case fatality rate reaching above $75 \%$. In the case of this virus, NiV-Bangladesh, transmission is associated with bat urinecontaminated date palm sap that is consumed by people (Broder et al., 2016; Homaira et al., 2010a; Homaira et al., 2010b; Luby et al., 2009; Rahman et al., 2012).

Natural infection of pigs can present with a spectrum of clinical signs, ranging from asymptomatic to mild-moderate respiratory diseases and, occasionally, encephalitis as part of a "porcine respiratory and encephalitis syndrome" (Nor et al., 2000). These mild, non-specific clinical presentations in pigs are problematic as they can easily go unnoticed until consequent human infections begin to surface.

Nipah virus, as recognized by the Coalition of Epidemic Preparedness Innovations (CEPI), is one of the viral threats of greatest concern for a human pandemic. It has also been proposed as one of the priority diseases of interest to the United States Department of Agriculture and the Department of Homeland Security, as well as being listed as a US Public Health Service Category A agent, due to its potential for use for intentional release as a component of bioterrorism. Due to the susceptibility of humans, high case-fatality rates for NiV disease, absence of human vaccines or 
therapeutics, this virus is classified as a Biosafety Level 4 (BSL4) pathogen (Chosewood and Wilson, 2009). Vaccine development, production, and efficacy testing are made even more complex due to the heightened regulation and strict constraints for biosafety and containment when working with this classification of pathogens, ultimately leading to a reluctance for the biologics industry to invest in products without government support, culminating in delays in research and in bringing an effective vaccine to market (Hardham and Lamichhane, 2013)

CEPI has allocated $\$ 460$ million (USD) for development, licensing, and stockpiling of human vaccines for what they have determined are the three highest pandemic threat agents (Nipah virus, Lassa Fever virus, and Middle Eastern Respiratory Syndrome coronavirus), this includes no provisions for prevention or control of Nipah virus in swine (Sifferlin, 2017). Due to the nature and consequences of NiV virus outbreaks in Southeast and South Asia, as well as the potential for unintentional or intentional introduction into other areas of the world, a swine vaccine able to eliminate viral shedding is of paramount importance and should be considered as an important control measure in pigs to ultimately control disease emergence in humans. If NiV should emerge or reemerge in a swine dense region, a highly efficacious vaccine for use in domestic swine would serve as a critical protective measure for both human and animal health, as well as a means of protecting the affected nation's food supply and economy. If cost-effective and available, a vaccine could also serve to protect small-holder investments in swine and maintaining food security, which is critical in the areas of likely reemergence.

The foundation of scientific knowledge based on many years of experimental work with NiV has provided the framework that should support successful development of a domestic swine vaccine. Numerous active and passive immunization approaches have been explored in a variety of species, as reviewed by Broder et al, 2016, including live-recombinant virus platforms, protein subunit, virus-like particles, and DNA vaccines (Broder et al., 2016). Most of these attempts have been focused on the development of NiV-specific neutralizing antibodies, however, some have evaluated both the ability to illicit an immune response as well as efficacy against challenge utilizing pigs. Initially, use of a recombinant canarypox virus with NiV F and $G$ glycoprotein genes inserts was evaluated in piglets with vaccination followed by intranasal challenge with live NiV. This approach demonstrated that prevention of 
NiV-mediated illness was achievable with minimal detection of viral nucleic acid being shed and, critically, live virus was not recoverable from vaccinated animals (Broder et al., 2016; Weingartl et al., 2006). It was then demonstrated that both arms of the immune response, cell-mediated and humoral, are critical for the protection of domestic swine against NiV infection (Pickering et al., 2016). Despite the promising results with the canarypox vector platform in swine and the numerous platforms evaluated in other species, a swine vaccine for NiV is still not available even with the continued threat of new spillover into this widespread species (Broder et al., 2016).

The desirable characteristics of a NiV vaccine to aid in the control of an outbreak in a swine dense region should be considered similar to other vaccines for use in combating transboundary animal diseases. There must be rapid onset of immunity, ideally through a single dose, and the induced immunity should be protective and long lasting. The vaccine should not interfere with booster vaccination or other vaccines being used in swine for endemic diseases and it should induce effective immunity in the face of maternal antibody so that it can be utilized in young animals. It should be safe to manufacture in BSL2 conditions. There should be a companion diagnostic assay available to determine infection versus vaccination status (DIVA). The product should be safe for use in food producing animals with a reasonably short withdrawal period for products for human consumption. Importantly, the vaccine should not be hazardous for humans that may be accidently exposed. To have sufficient product available to rapidly respond to an outbreak in swine that is either too large and/or too widespread to effectively stamp out through culling, a safe and efficacious NiV vaccine must be a component of a national or international veterinary stockpile. These countermeasures could be finished vaccine that is ready to deploy, stocks of vaccine antigen concentrate which can be readily converted into finished vaccine, and there must be the capability of rapidly producing large volumes of new vaccine.

\section{Stockpiling vaccines for emergency response}

Vaccine banks are typically stock of vaccine antigen concentrate, ready to be formulated into finished vaccines or ready-to-use products able to be rapidly deployed for emergency response with the overall goal of reducing the time between detection of disease and vaccination response. Vaccine banks were historically developed by FMD-free countries to control unexpected incursion of disease after 
vaccination campaigns end and disease-free status is gained (Barnett et al., 2010; Lei and McKercher, 1979; Lombard and Fussel, 2007). In fact, the first mention of this approach was following a devastating FMD outbreak in Great Britain in 1967-1968 after a commission charged with examining the outbreak made the recommendation to enhance preparedness for future control. Following the commission report, the British government purchased finished vaccine annually to cover several hundred thousand head of cattle for serotypes O, A, and C (Lombard and Fussel, 2007). This established the first known strategic antigen bank. Since this was finished, fully formulated vaccine, the shelf-life of the product required frequent replacement. In the 1970s, manufacturers developed novel methods to purify, concentrate, and store inactivated FMD antigen that allowed for resistance to freezing at ultra-low temperatures (liquid nitrogen). This process ultimately led to an extension of shelf-life when product was stored as vaccine antigen concentrate (VAC) (Barnett et al., 2010; Lombard and Fussel, 2007). A major drawback for the storage of VAC is the time required to take the VAC and finish (blending, formulating, filling) into a final vaccine that was ready for field deployment. Banks were principally established to combat inadvertent incursions of disease, but, in recent years, there has been an increased recognition of the possible consequences of deliberate use in agroterrorism (Barnett et al., 2010).

Regardless of the diseases to which the countermeasures are maintained, vaccine banks face many issues including strain or serotype selection, as well as the regulation of the manufacturing, storage, formulation, and testing of stored products, security, maintenance, monitoring, and disposal of products (Barnett et al., 2010). This regulation is even more complex when banks represent multiple countries, as each countries regulation and licensing requirements typically differ. Most vaccines utilized to combat TADs are produced for endemic country use and are made to order for a specific need by their manufacturer and provided formulated and ready to use. This typically occurs without surplus product and provides little flexibility to accommodate revisions to specifications at short notice (Barnett et al., 2010). This, of course, emphasizes the need for the vaccine banks. There are shared, desirable characteristics of vaccines and VAC meant for emergency use and kept in strategic reserves that should be considered when stockpiling a vaccine: 
- The vaccine should meet as many of the desirable characteristics for that agent as possible.

- There should be ongoing manufacture and sale of the products in endemic countries. This enables indefinite delivery and indefinite quantity contracts for just-in-time delivery, reducing the need for storage in traditional banks.

- The product should be based on antigen that is stable when stored as bulk VAC.

- Finished vaccine should have an established long shelf-life and stability of the finished product.

- The finished vaccine should be heat stable to reduce the need for extensive cold-chain management during deployment.

- There should be rapid scale up and manufacture processes in the regions of concern.

\section{Vaccination as a component of an effective Control Program}

This review, thus far, has focused on the need for efficacious vaccines for TADs, but vaccination is only one part of what is required for an effective Control Program in response to disease incursion. These programs must be designed and carried out by the competent veterinary authority for specific countries or regions, as there is no "one size fits all" response and every outbreak is different. Even with these differences, there are similar, overarching components that include the following:

- Biosecurity

- Surveillance and the ability to trace-back and trace-forward from known cases, to include:

- Animal identification

- Premises identification

- Movement records

- Vaccination protocols (species, age, frequency, monitoring of the development of immunity, matching of vaccine to the outbreak strain; for example, with FMDV)

- Vaccine quality control from production through administration (including cold chain maintenance, proper administration, records)

- The need to understand the characteristics of the vaccine:

- Expected efficacy in a naïve population

- Efficacy in the presence of maternal antibody 
- Duration of immunity

- Diagnostic assays capable of use for post-vaccination surveillance (DIVA)

- Ultimately, the ability to suppress transmission (the "reproduction ratio") in a population.

\section{Eurasian African Swine Fever Outbreak: uncontrolled spread of a TAD due to lack of a vaccine}

ASF emerged in the country of Georgia in 2007 where it was hypothesized that the virus

was introduced from contaminated pork products originating from a ship being fed to pigs in the region of the Port of Poti (Rowlands et al., 2008). After rapid spread involving both domestic pigs and wild boar into Armenia, Azerbaijan, and Iran, the outbreak reached the Russian Federation in early 2008. Since 2014, the virus has also been circulating in eastern Europe, including Estonia, Latvia, Lithuania, and Poland. The incursion in the Russian Federation brought the virus into a bordering country, putting the outbreak in close proximity to the People's Republic of China (Gogin et al., 2013; Sánchez-Vizcaíno et al., 2013).

Pig production and pork consumption are important to China for cultural and economic reasons as over 500 million pigs are produced within its borders annually, representing over half of the global pig population (Vergne et al., 2017). The proportion of pigs being produced in small, backyard farms raising less than 30 sows is estimated to be around $40 \%$ of the country's total production (Gilbert et al., 2015; McOrist et al., 2011). The factors that were proposed to put China at greatest risk for ASF introduction were discussed by Vergne et al, 2017. The risks specific to China included (1) the international movements of people in and out of the country and the potential for carrying contaminated or infected goods, (2) the significant increase in the demand for pork leading to large volumes of pork and pork products being imported into the country - both legally and illegally, (3) the widely distributed practice of raw swill feeding to subsidize and support pig production, and (4) the widespread population of wild boar throughout most of the country (Vergne et al., 2017).

In August, 2018, an incursion of ASF into Shenyang in northeastern China quickly spiraled into an unprecedented disaster and challenge to the Chinese swine industry 
(Wang et al., 2018; Zhou et al., 2018). The sequence of the circulating outbreak strain shares high homology with the Georgia 2007/1 strain and it is suggested that introduction occurred via smuggled pork originating from an Eastern European country (Ge et al., 2018; Wang et al., 2018). Since its introduction, ASF has been confirmed in numerous provinces across the country (Figure 3 ). The complexity of pork production and the fact that a major proportion of China's pigs are raised in smallholder farmyards with minimal biosecurity makes epidemiologic tracing a monumental task, but investigators have proposed that the virus has been circulating in country since at least March, 2018 (FAO, 2020; Normile, 2018).

Without a vaccine, control of ASF relies on early detection and rapid, local eradication efforts (Wang et al., 2018). The governmental response has been strong, involving the culling of sick and exposed animals; isolating infected farms; controlling the movement of live pigs and pig products; conducting extensive epidemiologic tracing; and disinfecting farms, processing facilities, and markets (Normile, 2018). Importantly, this response has also included trying to earn the cooperation of producers through immediate compensation for culled animals with the ultimate goal of preventing the slaughter of sick pigs and the sale and transport of contaminated meat that could perpetuate the continued spread of the virus (Normile, 2018; Wang et al., 2018). Even with this tremendous effort, ASF has spread rapidly throughout China and into neighboring countries (FAO, 2020; Zhao et al., 2019).

Researchers found that the particular ASF virus causing the outbreak in China is highly virulent, causing acute disease in 3-5 days in experimentally inoculated pigs with death occurring within 9 days and acute disease in contact animals in 9 days with death occurring within two weeks (Zhao et al., 2019). Further complicating the situation, a novel variant of the virus has begun spreading in the wild boar population representing the possibility of the introduction of a new strain into China or the evolution of a pre-existing strain ( $\mathrm{Li}$ et al., 2019). This will only serve to further complicate the situation, as well as any potential actions taken towards eradication.

Given the massive scale of the Chinese pork sector, the impact of ASF has the potential to be devastating. Introduction of this TAD has put a crucial protein source at risk and caused income insecurity for many families that are dependent on their household farms. There are many less obvious, indirect consequences of the 


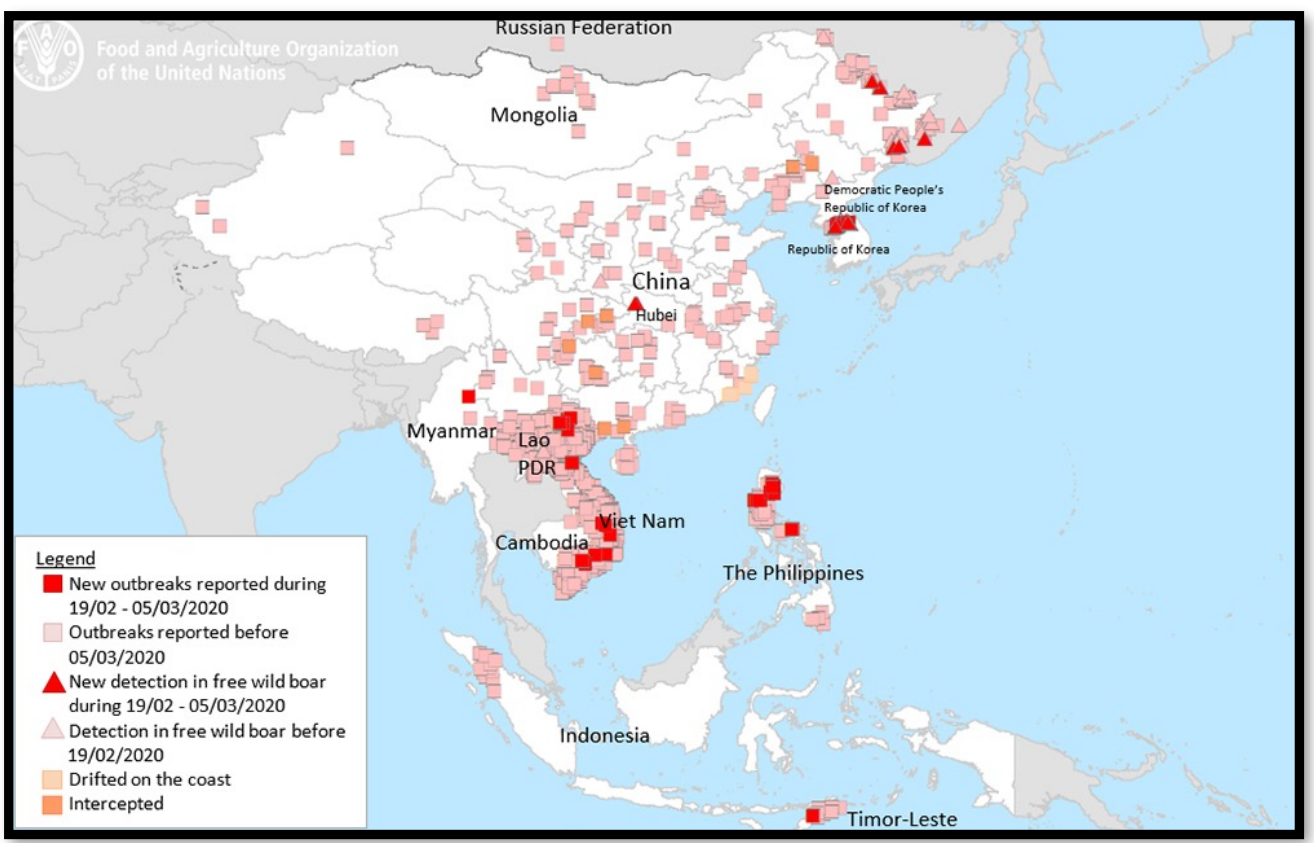

Figure 3. A map of the People's Republic of China showing the widespread distribution of African swine fever virus across numerous Chinese provinces and the spread to neighboring countries. From FAO, 2020.

outbreak that are beginning to be noticed. For instance, most of the unfractionated and low-molecular weight heparins used worldwide are produced in China from porcine mucosa. This outbreak and the consequent losses to the Chinese pig herd are jeopardizing the global availability of this critically important pharmaceutical (Vilanova et al., 2019).

Though various vaccines against ASF are being developed, there are no commercial products currently available for use (Wang et al., 2018). A safe and effective product must be considered a priority for cost-effective control measures to be a possibility in areas with similarly extensive swine populations. Emergence of ASF in Chinese pigs is an unprecedented disaster for China, as well as the rest of the world pork producers. If this virus remains in China, it will continue to pose a major threat to the rest of the world. ASF is a formidable TAD and its threat must not be taken lightly. All 
of these factors have set the stage for a costly, long-lasting, and challenging outbreak that will involve significant socioeconomic impacts and investment by the associated governments involved and the swine industry as a whole.

\section{Rinderpest: a complex interplay between animal and human health and a vaccination success story}

Rinderpest is an example of how a TAD that only affects animals can have a devastating impact on human health, but can ultimately be brought under control through the successful use of efficacious vaccines. Rinderpest virus is a member of the genus Morbillivirus with only one serotype, but three genetically distinct lineages that were found in different geographic areas. This virus causes acute, highly contagious disease of cattle, domesticated buffalo, and a variety of species of wildlife. The impact of Rinderpest led to the establishment of the first veterinary school in France in 1762 with the direct purpose of training specialists in the disease (Gilbert, 2009). In the 1880s, infected cattle originating in India introduced the virus to the African continent via the port of Massawa, Eritrea. This led to the death of $90 \%$ of the cattle in sub-Saharan Africa with widespread death in sheep and goats, as well as decimating many wildlife species. Mass human starvation ensued after the death of domestic livestock and draft animals, killing a third of the human population in Ethiopia and two-thirds of the Maasai people of Tanzania. With the drastic reduction in numbers of grazing animals, thickets formed in the savannah that served as breeding grounds for tsetse flies, the predominant vector for human African sleeping sickness (Moutou, 2014; Normile, 2008; Roth, 2011). The Great Ethiopian famine was not caused by a shortage of meat, it was caused by a shortage of grain secondary to the reduced draught power and reduced availability of manure caused by rinderpest (Pankhurst, 1966).

The first tissue culture produced vaccine against rinderpest was developed in 1960 (Plowright and Ferris, 1962). This vaccine was a success in that it conferred lifelong protective immunity to all lineages of the virus and had no reported adverse reactions, as well as being relatively inexpensive and easy to mass produce. Unfortunately, this vaccine required strict maintenance of cold chain, requiring logistically difficult refrigeration that is especially limiting in remote areas of Africa. This obstacle was overcome in 1981 by the modification of the lyophilization process of the same vaccine that resulted in a thermostable product with a shelf-life of 8 
months at $37^{\circ} \mathrm{C}$, which was sufficient to recommend its use in the field for up to 30 days without refrigeration. This allowed the vaccine to be delivered to remote areas and marginalized communities (Mariner et al., 2012). Although this improved vaccine continued to confer life-long immunity, it posed a challenge as it is impossible to differentiate between infected and vaccinated animals, complicating the overall goal of eradicating the disease. Due to this, the only option for monitoring the success of the local vaccination campaign was to halt the use of vaccine locally and monitor the area for resurgence of the virus. If the disease resurfaced, the campaign had to be reinstated (Gilbert, 2009).

The Global Rinderpest Eradication Program was established 1994 by the Food and Agriculture Organization of the United Nations (FAO) and the World Organization for Animal Health (OIE) as a large-scale international collaboration charged with coordination of vaccination campaigns, local and international trade restrictions, and disease surveillance. This new charge incorporated earlier, regional efforts with a focus on widespread vaccination and long-term, epidemiologic monitoring (Gilbert, 2009). After seventeen years, rinderpest was declared eradicated by both the FAO and the OIE in May, 2011 (Mariner et al., 2012; Njeumi et al., 2012). Rinderpest is only the second disease, following smallpox in humans, to be successfully eradicated through a coordinated, international campaign. This effort is one of veterinary medicine's greatest achievements and would not have been possible without the availability of an efficacious vaccine.

\section{Conclusion}

The global human population is growing at an exponential rate leading to the need for continued expansion of intensive food animal production to meet the world's increasing nutritional requirements. As a consequence of this increased production demand, the use of high volume, animal dense systems have expanded providing high quality protein at reduced costs. However, it also provides the opportunity for the rapid spread of disease, increased fitness pressure leading to mutation and adaptation of pathogens to new host species or increased disease severity in historically susceptible populations. This continues to drive the emergence and reemergence of diseases. The increase in "backyard" animal production in both rural and urban areas provides a critical source of high-quality protein and income to many, while also providing further opportunity for uncontrolled spread of disease and 
increasing the difficulty in pathogen control measures. The increase in all types of animal production to feed the increasing human population increases the urgency for the development and availability of efficacious vaccines for transboundary animal diseases

\section{References}

Abrams, C.C., Goatley, L., Fishbourne, E., Chapman, D., Cooke, L., Oura, C.A., Netherton,C.L., Takamatsu, H.-H., Dixon, L.K. (2013). Deletion of virulence associated genes from attenuated African swine fever virus isolate OUR T88/3 decreases its ability to protect against challenge with virulent virus. Virology 443, 99-105.

AbuBakar, S., Chang, L.-Y., Ali, A.M., Sharifah, S., Yusoff, K., Zamrod, Z. (2004). Isolation and molecular identification of Nipah virus from pigs. Emerging infectious diseases 10, 2228.

Achenbach, J., Gallardo, C., Nieto-Pelegrín, E., Rivera-Arroyo, B., Degefa-Negi, T., Arias, M., Jenberie, S., Mulisa, D., Gizaw, D., Gelaye, E. (2017). Identification of a new genotype of African swine fever virus in domestic pigs from Ethiopia. Transboundary emerging diseases 64, 1393-1404.

Adams, L.G., Khare, S., Lawhon, S.D., Rossetti, C.A., Lewin, H.A., Lipton, M.S., Turse, J.E., Wylie, D.C., Bai, Y., Drake, K.L. (2011). Enhancing the role of veterinary vaccines reducing zoonotic diseases of humans: linking systems biology with vaccine development. Vaccine 29, 7197-7206.

Afonso, C., Zsak, L., Carrillo, C., Borca, M., Rock, D. (1998). African swine fever virus NL gene is not required for virus virulence. General Virology 79, 2543-2547.

Alexandrov, T., Stefanov, D., Kamenov, P., Miteva, A., Khomenko, S., Sumption, K., Meyer-Gerbaulet, H., Depner, K. (2013). Surveillance of foot-and-mouth disease (FMD) in susceptible wildlife and domestic ungulates in Southeast of Bulgaria following a FMD case in wild boar. Veterinary microbiology 166, 84-90.

Amass, S.F., Mason, P.W., Pacheco, J.M., Miller, C.A., Ramirez, A., Clark, L.K., Ragland, D., Schneider, J.L., Kenyon, S.J. (2004). Procedures for preventing transmission of foot-and-mouth disease virus (O/TAW/97) by people. Veterinary microbiology 103, 143-149.

Argilaguet, J.M., Pérez-Martín, E., López, S., Goethe, M., Escribano, J., Giesow, K., Keil, G.M., Rodríguez, F. (2013). BacMam immunization partially protects pigs 
against sublethal challenge with African swine fever virus. Antiviral research 98, 61-65.

Argilaguet, J.M., Pérez-Martín, E., Nofrarías, M., Gallardo, C., Accensi, F., Lacasta, A., Mora, M., Ballester, M., Galindo-Cardiel, I., López-Soria, S. (2012). DNA vaccination partially protects against African swine fever virus lethal challenge in the absence of antibodies. PloS one 7.

Arzt, J., Baxt, B., Grubman, M., Jackson, T., Juleff, N., Rhyan, J., Rieder, E., Waters, R., Rodriguez, L. (2011a). The Pathogenesis of Foot-and-Mouth Disease II: Viral Pathways in Swine, Small Ruminants, and Wildlife; Myotropism, Chronic Syndromes, and Molecular Virus-Host Interactions. Transboundary and emerging diseases 58, 305-326.

Arzt, J., Juleff, N., Zhang, Z., Rodriguez, L. (2011b). The pathogenesis of foot-andmouth disease I: viral pathways in cattle. Transboundary and emerging diseases 58, 291-304.

Bachrach, H.L. (1968). Foot-and-mouth disease. Annual Reviews in Microbiology 22, 201-244.

Barnett, P., Bashiruddin, J., Hammond, J., Geale, D., Paton, D., 2010. Toward a global foot and mouth disease vaccine bank network. Revue scientifique et technique 29, 593.

Barnett, P., Geale, D., Clarke, G., Davis, J., Kasari, T. (2015a). A review of OIE country status recovery using vaccinate-to-live versus vaccinate-to-die foot-andmouth disease response policies I: Benefits of higher potency vaccines and associated NSP DIVA test systems in post-outbreak surveillance. Transboundary and emerging diseases 62, 367-387.

Barnett, P., Geale, D., Clarke, G., Davis, J., Kasari, T. (2015b). A review of OIE country status recovery using vaccinate-to-live versus vaccinate-to-die foot-andmouth disease response policies I: Benefits of higher potency vaccines and associated NSP DIVA test systems in post-outbreak surveillance. Transboundary emerging diseases 62, 367-387.

Bartley, L., Donnelly, C., Anderson, R. (2002). Review of foot-and mouth disease virus survival in animal excretions and on fomites (British Medical Journal Publishing Group).

Bellini, S., Rutili, D., Guberti, V. (2016). Preventive measures aimed at minimizing the risk of African swine fever virus spread in pig farming systems. Acta Veterinaria Scandinavica $58,82$. 
Blome, S., Gabriel, C., Beer, M. (2014). Modern adjuvants do not enhance the efficacy of an inactivated African swine fever virus vaccine preparation. Vaccine 32 , 3879-3882.

Borca, M., Carrillo, C., Zsak, L., Laegreid, W., Kutish, G., Neilan, J., Burrage, T., Rock, D. (1998). Deletion of a CD2-like gene, 8-DR, from African swine fever virus affects viral infection in domestic swine. Virology 72, 2881-2889.

Borca, M., Irusta, P., Carrillo, C., Afonso, C., Burrage, T., Rock, D.L. (1994a). African swine fever virus structural protein p72 contains a conformational neutralizing epitope. Virology 201, 413-418.

Borca, M., Kutish, G., Afonso, C., Irusta, P., Carrillo, C., Brun, A., Sussman, M., Rock, D.L. (1994b). An African swine fever virus gene with similarity to the Tlymphocyte surface antigen CD2 mediates hemadsorption. Virology 199, 463-468.

Brito, B., Rodriguez, L., Hammond, J., Pinto, J., Perez, A. (2017). Review of the global distribution of foot-and-mouth disease virus from 2007 to 2014. Transboundary and emerging diseases 64, 316-332.

Broder, C.C., Weir, D.L., Reid, P.A., 2016. Hendra virus and Nipah virus animal vaccines. Vaccine 34, 3525-3534.

Brown, C., Piccone, M., Mason, P., McKenna, T., Grubman, M. (1996). Pathogenesis of wild-type and leaderless foot-and-mouth disease virus in cattle. Virology 70 , 5638-5641.

Burmakina, G., Malogolovkin, A., Tulman, E., Zsak, L., Delhon, G., Diel, D., Shobogorov, N., Morgunov, Y.P., Morgunov, S.Y., Kutish, G. (2016). African swine fever virus serotype-specific proteins are significant protective antigens for African swine fever. General Virology 97, 1670-1675.

Cao, Y., Lu, Z., Liu, Z., 2016. Foot-and-mouth disease vaccines: progress and problems. Expert Review of Vaccines 15, 783-789.

Chapman, D.A., Tcherepanov, V., Upton, C., Dixon, L.K. (2008). Comparison of the genome sequences of non-pathogenic and pathogenic African swine fever virus isolates. General Virology 89, 397-408.

Ching, P.K.G., de Los Reyes, V.C., Sucaldito, M.N., Tayag, E., Columna-Vingno, A.B., Malbas, F.F., Jr., Bolo, G.C., Jr., Sejvar, J.J., Eagles, D., Playford, G., Dueger, E., Kaku, Y., Morikawa, S., Kuroda, M., Marsh, G.A., McCullough, S., Foxwell, A.R. (2015). Outbreak of henipavirus infection, Philippines, 2014. Emerging Infectious Diseases 21, 328-331. 
Chinsangaram, J., Mason, P.W., Grubman, M.J. (1998). Protection of swine by live and inactivated vaccines prepared from a leader proteinase-deficient serotype A12 foot-and-mouth disease virus. Vaccine 16, 1516-1522.

Chosewood, L.C., Wilson, D.E. (2009). Biosafety in microbiological and biomedical laboratories. US Department of Health and Human Services, Public Health Service, Centers ....

Chua, K.B., Koh, C.L., Hooi, P.S., Wee, K.F., Khong, J.H., Chua, B.H., Chan, Y.P., Lim, M.E., Lam, S.K. (2002). Isolation of Nipah virus from Malaysian Island flyingfoxes. Microbes and infection 4, 145-151.

Clavijo, A., Wright, P., Kitching, P. (2004). Developments in diagnostic techniques for differentiating infection from vaccination in foot-and-mouth disease. The Veterinary Journal 167, 9-22.

Clayton, B., Wang, L., Marsh, G. (2013). Henipaviruses: an updated review focusing on the pteropid reservoir and features of transmission. Zoonoses and public health 60, 69-83.

Colgrove, G., Haelterman, E., Coggins, L. (1969). Pathogenesis of African swine fever in young pigs. American Journal of Veterinary Research, 1343-1359.

Costard, S., Wieland, B., De Glanville, W., Jori, F., Rowlands, R., Vosloo, W., Roger, F., Pfeiffer, D.U., Dixon (2009). African swine fever: how can global spread be prevented? 364, 2683-2696.

De Kock, G., Robinson, E., Keppel, J. (1940). Swine fever in South Africa. Onderstepoort Journal of Veterinary Research 14.

De Villiers, E.P., Gallardo, C., Arias, M., Da Silva, M., Upton, C., Martin, R., Bishop, R.P. (2010). Phylogenomic analysis of 11 complete African swine fever virus genome sequences. Virology 400, 128-136.

DeTray, D. (1957). Persistence of viremia and immunity in African swine fever. American journal of veterinary research 18, 811-816.

Dixon, L.K., Chapman, D.A., Netherton, C.L., Upton, C. (2013). African swine fever virus replication and genomics. Virus research 173, 3-14.

Dixon, L.K., Escribano, J., Martins, C., Rock, D.L., Salas, M., Wilkinson, P.J. (2005). Asfarviridae. virus taxonomy, 135-143.

Dixon, L.K., Sun, H., Roberts, H. (2019). African swine fever. Antiviral Research 165, 34-41.

EFSA (2010). Scientific opinion on African swine fever. European Food Safety Authority 9, 1-149. 
FAO (1996). Prevention and Control of Transboundary Animal Diseases. Report of the FAO Expert Consultation on the Emergency Prevention System (EMPRES) for Transboundary Animal and Plant Pests and Diseases (Livestock Diseases Programme) including the Blueprint for Global Rinderpest Eradication, FAO Animal Production and Health Paper 133, Rome, Italy, 24-26 July.

FAO (2020). ASF Situation in Asia Update (Food and Agriclutre Organization of the United Nations).

FAO (2009). High Level Expert Forum-How to Feed the World in 2050, Economic and Social Development (Food and Agricultural Organization of the United Nations Rome).

Forman, A., Wardley, R., Wilkinson, P. (1982). The immunological response of pigs and guinea pigs to antigens of African swine fever virus. Archives of virology 74, 91-100.

Gallardo, C., Sánchez, E.G., Pérez-Núñez, D., Nogal, M., de León, P., Carrascosa, Á.L., Nieto, R., Soler, A., Arias, M.L., Revilla, Y. (2018). African swine fever virus (ASFV) protection mediated by NH/P68 and NH/P68 recombinant live-attenuated viruses. Vaccine 36, 2694-2704.

Ge, S., Li, J., Fan, X., Liu, F., Li, L., Wang, Q., Ren, W., Bao, J., Liu, C., Wang, H. (2018). Molecular characterization of African swine fever virus, China, 2018. Emerging infectious diseases 24, 2131.

Gilbert, M., Conchedda, G., Van Boeckel, T.P., Cinardi, G., Linard, C., Nicolas, G., Thanapongtharm, W., D'Aietti, L., Wint, W., Newman, S.H. (2015). Income disparities and the global distribution of intensively farmed chicken and pigs. PLoS One 10.

Gilbert, N. (2009). Cattle disease faces total wipeout; rinderpest goes the way of smallpox. Nature 462, 709-710.

Goatley, L.C., Reis, A.L., Portugal, R., Goldswain, H., Shimmon, G.L., Hargreaves, Z., Ho, C.-S., Montoya, M., Sánchez-Cordón, P.J., Taylor, G. (2020). A Pool of Eight Virally Vectored African Swine Fever Antigens Protect Pigs Against Fatal Disease. Vaccines 8, 234.

Gogin, A., Gerasimov, V., Malogolovkin, A., Kolbasov, D. (2013). African swine fever in the North Caucasus region and the Russian Federation in years 2007-2012. Virus research 173, 198-203.

Gomez-Puertas, P., Rodriguez, F., Oviedo, J.M., Ramiro-lbanez, F., Ruiz-Gonzalvo, F., Alonso, C., Escribano, J.M. (1996). Neutralizing antibodies to different proteins 
of African swine fever virus inhibit both virus attachment and internalization. virology 70, 5689-5694.

Grubman, M.J., Baxt, B. (2004). Foot-and-mouth disease. Clinical microbiology reviews $17,465-493$.

Hardham, J., Lamichhane, C. (2013). Biologics Industry Challenges for Developing Diagnostic Tests for the National Veterinary Stockpile, In: Vaccines and Diagnostics for Transboundary Animal Diseases. Karger Publishers, 39-52.

Hassell, J.M., Begon, M., Ward, M.J., Fèvre, E.M. (2017). Urbanization and disease emergence: dynamics at the wildlife-livestock-human interface. Trends in ecology evolution 32, 55-67.

Haydon, D., Samuel, A., Knowles, N. (2001). The generation and persistence of genetic variation in foot-and-mouth disease virus. Preventive Veterinary Medicine 51, 111-124.

Heldens, J., Patel, J., Chanter, N., Ten Thij, G., Gravendijck, M., Schijns, V., Langen, A., Schetters, T.P. (2008). Veterinary vaccine development from an industrial perspective. The Veterinary Journal 178, 7-20.

Homaira, N., Rahman, M., Hossain, M.J., Epstein, J.H., Sultana, R., Khan, M.S.U., Podder, G., Nahar, K., Ahmed, B., Gurley, E.S., Daszak, P., Lipkin, W.I., Rollin, P.E., Comer, J.A., Ksiazek, T.G., Luby, S.P. (2010a). Nipah virus outbreak with person-to-person transmission in a district of Bangladesh, 2007. Epidemiology and Infection 138, 1630-1636.

Homaira, N., Rahman, M., Hossain, M.J., Nahar, N., Khan, R., Rahman, M., Podder, G., Nahar, K., Khan, D., Gurley, E.S. (2010b). Cluster of Nipah virus infection, Kushtia district, Bangladesh, 2007. PLoS One 5.

Jamal, S.M., Belsham, G.J. (2013). Foot-and-mouth disease: past, present and future. Veterinary Research 44, 116.

Jones, B.A., Grace, D., Kock, R., Alonso, S., Rushton, J., Said, M.Y., McKeever, D., Mutua, F., Young, J., McDermott, J. (2013). Zoonosis emergence linked to agricultural intensification and environmental change. Proceedings of the National Academy of Sciences 110, 8399-8404.

Kihm, U., Ackermann, M., Mueller, H., Pool, R. 1987. Approaches to vaccination, In: African swine fever. Springer, 127-144.

King, D., Di Nardo, A., Henstock, M. (2018). OIE/FAO Foot-and-Mouth Disease Reference Laboratory Network: Annual Report 2018. In The Pirbright Institute: Woking, UK. 
King, K., Chapman, D., Argilaguet, J.M., Fishbourne, E., Hutet, E., Cariolet, R., Hutchings, G., Oura, C.A., Netherton, C.L., Moffat, K. (2011). Protection of European domestic pigs from virulent African isolates of African swine fever virus by experimental immunisation. Vaccine 29, 4593-4600.

Knight-Jones, T., Rushton, J. (2013). The economic impacts of foot and mouth disease-What are they, how big are they and where do they occur? Preventive veterinary medicine $112,161-173$.

Knight-Jones, T.J.D., Robinson, L., Charleston, B., Rodriguez, L.L., Gay, C.G., Sumption, K.J., Vosloo, W. (2016). Global Foot-and-Mouth Disease Research Update and Gap Analysis: 2 - Epidemiology, Wildlife and Economics. Transboundary and Emerging Diseases 63, 14-29.

Lacasta, A., Monteagudo, P.L., Jiménez-Marín, Á., Accensi, F., Ballester, M., Argilaguet, J., Galindo-Cardiel, I., Segalés, J., Salas, M.L., Domínguez, J. (2015). Live attenuated African swine fever viruses as ideal tools to dissect the mechanisms involved in viral pathogenesis and immune protection. Veterinary research 46, 135.

Lee, S.-Y., Lee, Y.-J., Kim, R.-H., Park, J.-N., Park, M.-E., Ko, M.-K., Choi, J.-H., Chu, J.-Q., Lee, K.-N., Kim, S.-M. (2017). Rapid engineering of foot-and-mouth disease vaccine and challenge viruses. Virology 91, e00155-00117.

Lei, J., McKercher, P. (1979). Report of the 1979 Session of the Research Group of the Standing Technical Committee of EUFMD, 12-14 June, Lindholm, Denmark. Appendix B1. Food and Agriculture Organization of the United Nations, Rome 24.

Leitão, A., Cartaxeiro, C., Coelho, R., Cruz, B., Parkhouse, R., Portugal, F.C., Vigário, J.D., Martins, C.L. (2001). The non-haemadsorbing African swine fever virus isolate ASFV/NH/P68 provides a model for defining the protective anti-virus immune response. General Virology 82, 513-523.

Li, L., Ren, Z., Wang, Q., Ge, S., Liu, Y., Liu, C., Liu, F., Hu, Y., Li, J., Bao, J. (2019). Infection of African swine fever in wild boar, China, 2018. Transboundary and emerging diseases 66, 1395-1398.

Lombard, M., Fussel, A. (2007). Antigen and vaccine banks: technical requirements and the role of the European antigen bank in emergency foot and mouth disease vaccination. Revue scientifique et technique-Office international des épizooties 26, 117.

Luby, S.P., Hossain, M.J., Gurley, E.S., Ahmed, B.-N., Banu, S., Khan, S.U., Homaira, N., Rota, P.A., Rollin, P.E., Comer, J.A. (2009). Recurrent zoonotic 
transmission of Nipah virus into humans, Bangladesh, 2001-2007. Emerging infectious diseases 15, 1229.

Manso-Ribeiro, J., Nunes-Petisca, J., Lopez-Frazao, F., Sobral, M. (1963). Vaccination against ASF. Bull Off Int Epizoot 60, 921-937.

Mariner, J.C., House, J.A., Mebus, C.A., Sollod, A.E., Chibeu, D., Jones, B.A., Roeder, P.L., Admassu, B., van't Klooster, G.G. (2012). Rinderpest eradication: appropriate technology and social innovations. Science 337, 1309-1312.

Mason, P., Piccone, M., McKenna, T.S.-C., Chinsangaram, J., Grubman, M. (1997). Evaluation of a live-attenuated foot-and-mouth disease virus as a vaccine candidate. Virology 227, 96-102.

McOrist, S., Khampee, K., Guo, A. (2011). Modern pig farming in the People's Republic of China: growth and veterinary challenges. Revue Scientifique et Technique-OIE 30, 961.

McVicar, J., 1984. Quantitative aspects of the transmission of African swine fever. American Journal of Veterinary Research 45, 1535-1541.

Mebus, C., Dardiri, A. (1980). Western hemisphere isolates of African swine fever virus: asymptomatic carriers and resistance to challenge inoculation. American journal of veterinary research 41, 1867-1869.

Mebus, C.A. (1988). African swine fever, In: Advances in virus research. Elsevier, 251-269.

Meeusen, E.N., Walker, J., Peters, A., Pastoret, P.-P., Jungersen, G. (2007). Current status of veterinary vaccines. Clinical microbiology reviews 20, 489-510.

Montgomery, R.E. (1921). On a form of swine fever occurring in British East Africa (Kenya Colony). Journal of comparative pathology therapeutics 34, 159-191.

Moutou, F. (2014). The second eradication: Rinderpest. Bulletin de la Société de pathologie exotique 107, 137-138.

Mulumba-Mfumu, L., Goatley, L., Saegerman, C., Takamatsu, H.H., Dixon, L. (2016). Immunization of African Indigenous Pigs with Attenuated Genotype I African Swine Fever Virus OURT 88/3 Induces Protection Against Challenge with Virulent Strains of Genotype I. Transboundary emerging diseases 63, e323-e327.

Mur, L., Gallardo, C., Soler, A., Zimmermman, J., Pelayo, V., Nieto, R., SánchezVizcaíno, J.M., Arias, M. (2013). Potential use of oral fluid samples for serological diagnosis of African swine fever. Veterinary microbiology 165, 135-139. 
Nampanya, S., Khounsy, S., Abila, R., Young, J., Bush, R., Windsor, P. (2016). Financial impacts of foot-and-mouth disease at village and national levels in Lao PDR. Transboundary and Emerging Diseases 63, e403-e411.

Neilan, J., Zsak, L., Lu, Z., Kutish, G., Afonso, C., Rock, D.L. (2002). Novel swine virulence determinant in the left variable region of the African swine fever virus genome. virology 76, 3095-3104.

Neilan, J.G., Zsak, L., Lu, Z., Burrage, T.G., Kutish, G.F., Rock, D.L. (2004). Neutralizing antibodies to African swine fever virus proteins p30, p54, and p72 are not sufficient for antibody-mediated protection. virology 319, 337-342.

Netherton, C.L., Goatley, L.C., Reis, A.L., Portugal, R., Nash, R.H., Morgan, S.B., Gault, L., Nieto, R., Norlin, V., Gallardo, C. (2019). Identification and immunogenicity of African swine fever virus antigens. Frontiers in immunology 10 , 1318.

Njeumi, F., Taylor, W., Diallo, A., Miyagishima, K., Pastoret, P.-P., Vallat, B., Traore, M. (2012). The long journey: a brief review of the eradication of rinderpest. Rev Sci Tech 31, 729-724.

Nor, M.M., Gan, C., Ong, B. (2000). Nipah virus infection of pigs in peninsular Malaysia. Revue Scientifique et Technique-Office International des Epizooties 19, 160-165.

Normile, D. (2008). Driven to extinction (Science, American Association for the Advancement of Science).

Normile, D. (2018). Arrival of deadly pig disease could spell disaster for China (Science, American Association for the Advancement of Science).

O'Donnell, V., Holinka, L.G., Gladue, D.P., Sanford, B., Krug, P.W., Lu, X., Arzt, J., Reese, B., Carrillo, C., Risatti, G.R. (2015a). African swine fever virus Georgia isolate harboring deletions of MGF360 and MGF505 genes is attenuated in swine and confers protection against challenge with virulent parental virus. Virology 89, 6048-6056.

O'Donnell, V., Holinka, L.G., Krug, P.W., Gladue, D.P., Carlson, J., Sanford, B., Alfano, M., Kramer, E., Lu, Z., Arzt, J. (2015b). African swine fever virus Georgia 2007 with a deletion of virulence-associated gene 9GL (B119L), when administered at low doses, leads to virus attenuation in swine and induces an effective protection against homologous challenge. Virology 89, 8556-8566.

O’Donnell, V., Holinka, L.G., Sanford, B., Krug, P.W., Carlson, J., Pacheco, J.M., Reese, B., Risatti, G.R., Gladue, D.P., Borca, M.V. (2016). African swine fever virus 
Georgia isolate harboring deletions of 9GL and MGF360/505 genes is highly attenuated in swine but does not confer protection against parental virus challenge. Virus Research 221, 8-14.

OIE (2013). Manual of Diagnostic Tests and Vaccines for Terrestrial Animals. Paris: OIE. 2013. In Foot and Mouth Disease.

Otte, M., Nugent, R., McLeod, A. (2004). Transboundary animal diseases: Assessment of socio-economic impacts and institutional responses. Food and Agriculture Organization (FAO), 119-126.

Oura, C., Denyer, M., Takamatsu, H., Parkhouse, R. (2005). In vivo depletion of CD8+ T lymphocytes abrogates protective immunity to African swine fever virus. General Virology 86, 2445-2450.

Pankhurst, R., 1966. The great Ethiopian famine of 1888-1892: a new assessment. Journal of the History of Medicine and Allied Sciences 21, 95-124.

Pendell, D.L., Marsh, T.L., Coble, K.H., Lusk, J.L., Szmania, S.C. (2015). Economic assessment of FMDv releases from the national bio and agro defense facility. PLoS One 10.

Pickering, B.S., Hardham, J.M., Smith, G., Weingartl, E.T., Dominowski, P.J., Foss, D.L., Mwangi, D., Broder, C.C., Roth, J.A., Weingartl, H.M. (2016). Protection against henipaviruses in swine requires both, cell-mediated and humoral immune response. Vaccine 34, 4777-4786.

Plowright, W., Ferris, R. (1962). Studies with rinderpest virus in tissue culture: the use of attenuated culture virus as a vaccine for cattle. Research in Veterinary Science 3, 172-182.

Quembo, C.J., Jori, F., Vosloo, W., Heath, L. (2018). Genetic characterization of African swine fever virus isolates from soft ticks at the wildlife/domestic interface in Mozambique and identification of a novel genotype. Transboundary emerging diseases 65, 420-431.

Rahman, M.A., Hossain, M.J., Sultana, S., Homaira, N., Khan, S.U., Rahman, M., Gurley, E.S., Rollin, P.E., Lo, M.K., Comer, J.A. (2012). Date palm sap linked to Nipah virus outbreak in Bangladesh, 2008. Vector-Borne and Zoonotic Diseases 12, 65-72.

Reis, A.L., Abrams, C.C., Goatley, L.C., Netherton, C., Chapman, D.G., SanchezCordon, P., Dixon, L.K. (2016). Deletion of African swine fever virus interferon inhibitors from the genome of a virulent isolate reduces virulence in domestic pigs and induces a protective response. Vaccine 34, 4698-4705. 
Robinson, L., Knight-Jones, T.J.D., Charleston, B., Rodriguez, L.L., Gay, C.G., Sumption, K.J., Vosloo, W. (2016). Global Foot-and-Mouth Disease Research Update and Gap Analysis: 3 - Vaccines. Transboundary and Emerging Diseases 63, 30-41.

Rock, D.L. (2017). Challenges for African swine fever vaccine development. Veterinary Microbiology 206, 52-58.

Rodríguez, J.M., Yáñez, R.J., Almazán, F., Viñuela, E., Rodríguez, J.F. (1993). African swine fever virus encodes a CD2 homolog responsible for the adhesion of erythrocytes to infected cells. Virology 67, 5312-5320.

Rodriguez, L.L., Grubman, M.J. (2009). Foot and mouth disease virus vaccines. Vaccine 27, D90-D94.

Rossiter, P.B., Al Hammadi, N. (2009). Living with transboundary animal diseases (TADs). Tropical animal health and production 41, 999.

Roth, J.A. (2011). Veterinary vaccines and their importance to animal health and public health. Procedia in Vaccinology 5, 127-136.

Roth, J.R., Galyon, J (2019). Emerging Diseases of Food Animals Threaten Global Food Security. In International Affairs Forum: Food and Water Security (Center for International Relations).

Rowlands, R.J., Michaud, V., Heath, L., Hutchings, G., Oura, C., Vosloo, W., Dwarka, R., Onashvili, T., Albina, E., Dixon, L.K. (2008). African swine fever virus isolate, Georgia, 2007. Emerging infectious diseases 14, 1870.

Rweyemamu, M., Roeder, P., Mackay, D., Sumption, K., Brownlie, J., Leforban, Y., Valarcher, J.F., Knowles, N., Saraiva, V. (2008). Epidemiological patterns of footand-mouth disease worldwide. Transboundary and emerging diseases 55, 57-72.

Sánchez-Vizcaíno, J.M., Mur, L., Martínez-López, B. (2013). African swine fever (ASF): five years around Europe. Veterinary Microbiology 165, 45-50.

Sifferlin, A. (2017). This new group wants to stop pandemics before they start. Time. Retrieved June 8, 2020, from https://time.com/4639245/cepi-ebola-zika-epidemic/.

Speer, N. (2019). The impact of African swine fever goes far beyond just the disease. Beef magazine. Retrieved June 8, 2020, from https://www.beefmagazine.com/ outlook/china-pork-production-just-how-bad-it.

Stenfeldt, C., Segundo, D.S., de los Santos, T., Rodriguez, L.L., Arzt, J. (2016). The pathogenesis of foot-and-mouth disease in pigs. Frontiers in veterinary science 3 , 41. 
Stone, S., Hess, W. (1967). Antibody response to inactivated preparations of African swine fever virus in pigs. American journal of veterinary research 28, 475.

Thomas, L.F., Bishop, R.P., Onzere, C., Mcintosh, M.T., Lemire, K.A., de Glanville, W.A., Cook, E.A.J., Fèvre, E.M. (2016). Evidence for the presence of African swine fever virus in an endemic region of Western Kenya in the absence of any reported outbreak. BMC veterinary research 12, 192.

Thompson, D., Muriel, P., Russell, D., Osborne, P., Bromley, A., Rowland, M., Creigh-Tyte, S., Brown, C. (2002). Economic costs of the foot and mouth disease outbreak in the United Kingdom in 2001. Revue scientifique et technique-Office international des epizooties 21, 675-685.

Thomson, G., Vosloo, W., Bastos, A. (2003). Foot and mouth disease in wildlife. Virus research 91, 145-161.

Vergne, T., Chen-Fu, C., Li, S., Cappelle, J., Edwards, J., Martin, V., Pfeiffer, D.U., Fusheng, G., Roger, F.L. (2017). Pig empire under infectious threat: risk of African swine fever introduction into the People's Republic of China. Veterinary Record.

Vilanova, E., Tovar, A.M., Mourão, P.A. (2019). Imminent risk of a global shortage of heparin caused by the African Swine Fever afflicting the Chinese pig herd. Journal of Thrombosis and Haemostasis 17, 254-256.

Villeda, C., Gómez-Villamandos, J., Williams, S., Hervas, J., Wilkinson, P., Vinuela, E. (1995). The role of fibrinolysis in the pathogenesis of the haemorrhagic syndrome produced by virulent isolates of African swine fever virus. Thrombosis haemostasis $73,112-117$.

Villeda, C., Williams, S., Wilkinson, P., Vinuela, E. (1993). Consumption coagulopathy associated with shock in acute African swine fever. Archives of virology 133, 467-475.

Wang, T., Sun, Y., Qiu, H.J. (2018). African swine fever: an unprecedented disaster and challenge to China. Infectious diseases of poverty $7,111$.

Weingartl, H.M., Berhane, Y., Caswell, J.L., Loosmore, S., Audonnet, J.-C., Roth, J.A., Czub, M., (2006). Recombinant nipah virus vaccines protect pigs against challenge. Journal of virology $80,7929-7938$.

Wilkinson, P., Wardley, R., Williams, S. (1983). Studies in pigs infected with African swine fever virus (Malta/78). In: CEC/FAO Expert Consultation on African Swine Fever Research, 74-84. 
Zhao, D., Liu, R., Zhang, X., Li, F., Wang, J., Zhang, J., Liu, X., Wang, L., Zhang, J., $\mathrm{Wu}, \mathrm{X}$. (2019). Replication and virulence in pigs of the first African swine fever virus isolated in China. Emerging microbes \& infections 8, 438-447.

Zhou, X., Li, N., Luo, Y., Liu, Y., Miao, F., Chen, T., Zhang, S., Cao, P., Li, X., Tian, K. (2018). Emergence of African swine fever in China, 2018. Transboundary and emerging diseases $65,1482-1484$. 